\title{
TITLE:
}

\section{Poly(arylene-ethynylene)s containing dithia[3.3]metaphane}

$\operatorname{AUTHOR}(\mathrm{S})$ :

Morisaki, Yasuhiro; Ishida, Tamao; Chujo, Yoshiki

\section{CITATION:}

Morisaki, Yasuhiro ...[et al]. Poly(arylene-ethynylene)s containing dithia[3.3]metaphane. Comptes Rendus Chimie 2009, 12(3-4): 332-340

ISSUE DATE:

2009-03

URL:

http://hdl.handle.net/2433/123390

\section{RIGHT:}

Copyright (c) 2008 Elsevier; This is not the published version. Please cite only the published version.; この論文は出版社版でありません。引用の 際には出版社版をご確認ご利用ください。 


\title{
Poly(arylene-ethynylene)s Containing Dithia[3.3]metaphane
}

\author{
Yasuhiro Morisaki*, Tamao Ishida, and Yoshiki Chujo* \\ Department of Polymer Chemistry, Graduate School of Engineering, Kyoto University, \\ Katsura, Nishikyo-ku, Kyoto 615-8510, Japan \\ E-mail address: ymo@chujo.synchem.kyoto-u.ac.jp (Y. Morisaki) \\ chujo@chujo.synchem.kyoto-u.ac.jp (Y. Chujo)
}

\begin{abstract}
This account provides a summary of our research on poly(arylene-ethynylene)s (PAEs) containing dithia[3.3]metaphane such as dithia[3.3]metacyclophane and dithia[3.3](2,6)pyridinophane. Synthetic procedures, characterizations, optical properties, and their potential applications in a recyclable catalyst and metal sensor will be presented.
\end{abstract}

Keywords: Poly(arylene-ethynylene) (PAE); Dithia[3.3]metacyclophane; Dithia[3.3](2,6)pyridinophane; Syn-anti isomerization 


\section{Introduction}

Recently, the synthesis, structure, and physical properties of polyynes and acetylenic compounds have attracted increasing attention [1]. The carbon-carbon triple bond is a crucial building block for the preparation of carbon-rich compounds as well as $\pi$-conjugated molecules. Especially, in the field of polymer chemistry, it is an essential unit to construct a rigid rod $\pi$-conjugated framework. Among $\pi$-conjugated polymers containing carbon-carbon triple bonds in their main chain, poly( $p$-arylene-ethynylene)s (PAEs) have attracted considerable attention, and they are currently one of the most important classes of conjugated polymers used as emitting, charge-transporting, conducting, and sensing materials [2]. PAEs with relatively high molecular weights can be readily prepared by a palladium-catalyzed coupling reaction [3] and the molybdenum-catalyzed metathesis [4]. PAEs with properties depending on their intended application have been developed by incorporating various aromatic compounds into their backbone.

(Chart 1)

In the past few years, we have employed [2.2]paracyclophane as the key unit for the construction of through-space conjugated PAEs [5] and aromatic ring-layered PAEs [6] (Chart 1). We evaluated that [2.2]paracyclophane-containing PAEs exhibited an extension of $\pi$-conjugation length via a through-bond as well as a through-space interaction; this prompted us to incorporate other cyclophane compounds into PAEs in order to take advantage of their characteristics. Thus, we have focused on dithia[3.3]metaphanes and its derivatives because they are of great interest; these compounds exhibit a unique transannular $\pi-\pi$ interaction between two aromatic rings and also exhibit conformational flexibility $[7,8]$. Particularly, syn-anti ring inversion of two aromatic rings is the most interesting point in dithia[3.3]metaphane chemistry. Depending on the applicability of dithia[3.3]metaphanes, they can be considered to be promising building blocks for the aryl unit of PAEs. On the contrary, the structurally straight and rigid carbon-carbon triple bond is the best way to link dithia[3.3]metaphane units rather than a carbon-carbon double bond and other linkers in order 
to take advantage of their unique features. This account summarizes our study on PAEs comprising dithia[3.3]metaphane. The synthetic procedures, characterizations, and optical properties of dithia[3.3]metacyclophane- and dithia[3.3](2,6)pyridinophane-containing PAEs $[9,10]$ are introduced. 


\section{PAE containing dithia[3.3]metacyclophane}

\subsection{Synthesis}

A key monomer, 6,15-dibromo-2,11-dithia[3.3]metacyclophane 1, was synthesized by the direct coupling reaction of 5-bromo-1,3-benzenedimethanethiol with 5-bromo-1,3-bis(bromomethyl)benzene in 42\% yield [9a,11]. As shown in Scheme 1, the reaction of 1 with diethynylbenzene 2 in the presence of a catalytic amount of $\operatorname{Pd}\left(\mathrm{PPh}_{3}\right)_{4}$ and $\mathrm{CuI}$ yielded a corresponding polymer 3 in $47 \%$ isolated yield with a number-average molecular weight of 14000 (PDI $=1.9$ by GPC, polystyrene standards). Polymer 3 was soluble in common organic solvents, and it was thermally and air stable both in solution and in the solid state.

(Scheme 1)

\subsection{Characterization and stereochemistry}

Model compound 4, which has a dithia[3.3]metacyclophane core, was prepared in order to study the stereochemistry and the optical properties of the polymer [9a]. Figure 1 shows the ${ }^{1} \mathrm{H}$ NMR spectra $(270 \mathrm{MHz})$ of monomer $\mathbf{1}$, compound $\mathbf{4}$, and polymer 3 in $\mathrm{CDCl}_{3}$ at $25{ }^{\circ} \mathrm{C}$. In the ${ }^{1} \mathrm{H}$ NMR spectrum of 1 (Figure 1A), the singlet signals at 7.05 and $6.96 \mathrm{ppm}$ are assignable to the outer and inner aromatic protons $\left(\mathrm{H}_{o}\right.$ and $\mathrm{H}_{i}$, Figure 1$)$, respectively. It is known that $\mathrm{H}_{i}$ of the anti conformation appears at 5 6 ppm due to a ring current effect [12]. In addition, the bridge methylene protons of 1 appeared at $\delta=3.73 \mathrm{ppm}$ as a sharp singlet peak (Figure 1A). These results imply that the rapid syn-[anti]-syn interconversion of aromatic rings occurs in a solution.

(Structure of compound 4)

(Figure 1)

The ${ }^{1} \mathrm{H}$ NMR spectrum of compound $\mathbf{4}$ and polymer $\mathbf{3}$ also exhibited conformational flexibility, as shown in Figure 1B and C, respectively. In both cases, the inner protons $\mathrm{H}_{i}$ 
appeared at normal aromatic range and the bridged methylene protons appeared as a singlet peak at around $3.7 \mathrm{ppm}$. In dithia[3.3]metacyclophane units, the rapid syn-[anti]-syn interconversion of aromatic groups occurs in a solution, although they are incorporated into the PAE polymer backbone.

\subsection{Reactivity}

Dithia[3.3]metacyclophanes have been used as synthetic precursors for [2.2] metacyclophanes and [2.2]metacyclophane-dienes

Dithia[3.3]metacyclophane-2,2',11,11'-tetraoxide is an intermediate compound formed during the synthesis of [2.2]metacyclophane, which can be easily prepared by the oxidation reaction of 2,11-dithia[3.3]metacyclophane. According to a method described in the literature (Scheme 2), oxidation was carried out by adding an excess amount of $m$-CPBA to polymer 3 in $\mathrm{CHCl}_{3}[9 \mathrm{~b}, 13,14]$. Polymer $\mathbf{3}$ was easily oxidized to produce polymer $\mathbf{5}$ in $93 \%$ yield, and the ${ }^{1} \mathrm{H},{ }^{13} \mathrm{C}$ NMR and FTIR spectra revealed that all sulfur atoms were completely converted to sulfones. Additionally, the ${ }^{1} \mathrm{H}$ NMR spectrum of polymer 5 exhibited rapid syn-[anti]-syn isomerization of dithia[3.3]metacyclophane tetraoxide units (Figure 1D), same as that in polymer 3 [9b].

(Scheme 2)

\subsection{Optical properties}

The optical properties of polymer 3 and compounds 4 and $\mathbf{6}[5 \mathrm{a}]$ were examined. In Figure 2, the UV-vis absorption spectrum of polymer $\mathbf{3}$ in a dilute $\mathrm{CHCl}_{3}$ solution at room temperature exhibited absorption peaks at 311 and $372 \mathrm{~nm}$, which agreed with the absorption peak of the PAE backbone. The absorption maxima of compounds $\mathbf{4}$ and $\mathbf{6}$ were observed at 331 and $370 \mathrm{~nm}$, respectively, as shown in Figure 2. The maximum absorption peak of polymer $3\left(\lambda_{\max }=372 \mathrm{~nm}\right)$ was observed at almost the same wavelength as that of 4 , and the absorption edge of $\mathbf{3}$ had a longer wavelength than that of $\mathbf{4}$ Incidentally, [2.2]paracyclophane-containing PAE (Chart $1, \mathrm{R}=\mathrm{C}_{12} \mathrm{H}_{25}$ ) exhibited a maximum absorption 
peak at around $385 \mathrm{~nm}$ [5a]. Due to the flipping motion of dithia[3.3]metacyclophane units in polymer $\mathbf{3}$, an ineffective extension of the $\pi$-conjugation length of the polymer chain is observed.

(Structure of 6)

(Figures 2 and 3)

In the fluorescence emission spectra of polymer 3 and compound $\mathbf{6}$ in dilute $\mathrm{CHCl}_{3}$ solution $\left(1.0 \times 10^{-5} \mathrm{M}\right)$ at room temperature on excitation at absorption maximum, the emission peaks were observed at around 450 and $410 \mathrm{~nm}$ in the visible blue region, respectively (Table 1, Figure 3). A large Stokes shift of polymer $\mathbf{3}$ was derived from a nonradiative transition caused by molecular movements such as phane-flipping, $-\mathrm{CH}_{2}-\mathrm{S}-\mathrm{CH}_{2}-$ bridge-wobbling. The above-mentioned emission spectra exhibited vibrational structures that were mirror images of the absorption spectra. It is well known that the emission of cyclophane compounds can correspond to two situations, i.e., emission in a monomer (chromophore) state or that in a phane state (excimer-like emission) $[15,16]$. The emission peak of polymer 3 exhibited a vibrational structure at $\lambda=405,440$, and around $470(\mathrm{sh}) \mathrm{nm}$, which was almost the same as that exhibited by compound 6 at $\lambda_{\max }=398$ and $415 \mathrm{~nm}$. This result implies that the emission of polymer 3 occurs in the monomer state rather than the phane state. In addition, the fluorescence quantum efficiency of polymer $\mathbf{3}$ was found to be 0.51 in the $\mathrm{CHCl}_{3}$ solution at room temperature. 


\section{PAE containing dithia $[3.3](2,6)$ pyridinophane}

\subsection{Synthesis}

Dithia[3.3](2,6)pyridinophane, which has two pyridine rings linked by two $-\mathrm{CH}_{2}-\mathrm{S}-\mathrm{CH}_{2}-$ bridges, exhibits a unique property in addition to conformational flexibility and transannular $\pi-\pi$ interaction. Moreover, dithia[3.3](2,6)pyridinophane can be used as a bidentate nitrogen ligand for transition metals. As shown in Scheme 3, the polymerization of monomer $\mathbf{7}$ with 1,4-diethynyl-2,5-dioctyloxybenzene $\mathbf{8}$ was carried out in toluene-diisopropylamine solution in the presence of a catalytic amount of $\mathrm{PdCl}_{2}\left(\mathrm{PPh}_{3}\right)_{2} / \mathrm{PCy} / \mathrm{CuI}(\mathrm{Cy}=$ cyclohexyl $)$ to produce the corresponding PAE 9 in $81 \%$ yield with $M_{\mathrm{n}}=4200$ [10]. Metal species could be removed by washing the polymer solution with aqueous $\mathrm{NH}_{3}$ three times, which was confirmed by the ${ }^{1} \mathrm{H}$ NMR spectrum (vide infra).

\section{(Scheme 3)}

\subsection{Characterization and stereochemistry}

Figures $4 \mathrm{~A}$ and $\mathrm{B}$ show the ${ }^{1} \mathrm{H}$ NMR spectra of monomer 7 and polymer 9 in a $\mathrm{CDCl}_{3}$ solution, respectively. The chemical shift of the bridged methylene protons $\left(-\mathrm{CH}_{2}-\mathrm{S}-\mathrm{CH}_{2}-\right)$ of monomer 7 appeared as a sharp singlet peak at $\delta=3.9 \mathrm{ppm}$. This indicates that rapid ring syn-anti flipping occurs in the solution of monomer 7. In the ${ }^{1} \mathrm{H}$ NMR spectrum of polymer 9 in $\mathrm{CDCl}_{3}$ (Figure 5B), the signals of the octyloxy chains were observed at $\delta=0.87, \delta=$ $1.2-1.9$, and $\delta=3.8 \mathrm{ppm}$ as a shoulder peak overlapped with the bridged methylene protons of the dithia[3.3](2,6)pyridinophane unit. Thus, the dithia[3.3](2,6)pyridinophane units in polymer 9 are also flexible, and the rapid syn-anti interconversion of pyridine rings is observed in the solution of polymer 9 .

(Figure 4) 


\subsection{Complexation behavior}

It is reported that the complexation reaction between dithia[3.3](2,6)pyridinophane and the palladium complex $\mathrm{PdCl}_{2}(\mathrm{PhCN})_{2}$ produces $\mathrm{PdCl}_{2}$ (dithia[3.3](2,6)pyridinophane) [17]. Therefore, we examined the complexation reaction between polymer 9 and $\mathrm{PdCl}_{2}\left(\mathrm{PhCN}_{2}\right.$. As shown in Scheme 4, polymer 9 was treated with an equimolar amount of $\mathrm{PdCl}_{2}(\mathrm{PhCN})_{2}$ in $\mathrm{CH}_{2} \mathrm{Cl}_{2}$ solution, and a brown-colored polymer complex $\mathbf{1 0}$ was precipitated in $91 \%$ yield. This polymer complex 10 was insoluble in $\mathrm{CH}_{2} \mathrm{Cl}_{2}, \mathrm{CHCl}_{3}$, and $\mathrm{THF}$, and it was slightly soluble in aprotic solvents such as DMF and DMSO. Figure $4 \mathrm{C}$ shows the ${ }^{1} \mathrm{H}$ NMR spectrum of polymer complex $\mathbf{1 0}$ in DMSO- $d_{6}$. In Figure $4 \mathrm{C},-\mathrm{CH}_{2}-\mathrm{S}-\mathrm{CH}_{2}-$ methylene protons of polymer 9 (Figure 4B) were separated into two signals at $\delta=4.7$ and $6.0 \mathrm{ppm}$, which were consistent with those of $\mathrm{PdCl}_{2}$ (dithia[3.3](2,6)pyridinophane) (at $\delta=4.72$ and $6.07 \mathrm{ppm}$ ) reported by Tsuge and coworkers [17]. The formation of the palladium complex caused dithia[3.3] $(2,6)$ pyridinophane units to fold the syn conformation. The complexation efficiencies were calculated to be $80 \%$ by comparing with the integral ratio of separated methylenes of coordinated pyridinophane units $(\delta=4.7$ and $6.0 \mathrm{ppm})$ and methylenes of unreacted pyridinophane units $(\delta=4.0 \mathrm{ppm})$. Due to the low solubility of polymer complex 10 in $\mathrm{CH}_{2} \mathrm{Cl}_{2}$, it was precipitated from the reaction mixture during the complexation process.

(Scheme 4)

\subsection{Catalytic activity of polymer complex 10}

The catalytic activity of the obtained polymer complex $\mathbf{1 0}$ was examined. In the presence of a catalytic amount of the palladium-pyridinophane units of polymer complex $\mathbf{1 0}$, the Heck coupling reaction between phenyl iodide and $t$-butyl acrylate was carried out smoothly to produce the corresponding $t$-butyl cinnamate with high yields (Table 1). The best result was obtained when $1.0 \mathrm{~mol} \%$ of palladium-pyridinophane units were used (entry 1 , $98 \%$ yield), while only $0.01 \mathrm{~mol} \%$ of palladium-pyridinophane units exhibited a high catalytic activity to give $t$-butyl cinnamate in $86 \%$ yield (entry 7 ). The catalytic activity of polymer complex $\mathbf{1 0}$ at room temperature also yielded a good result (entry 4). After the 
reaction, polymer complex $\mathbf{1 0}$ was purified by reprecipitation from an excess amount of $\mathrm{CHCl}_{3}$ solution and used for the next reaction. The results of this recycling study are also listed in Table 1, entries 5 and 6. Polymer complex $\mathbf{1 0}$ maintained the catalytic activity in the 3 rd cycle and yielded $t$-butyl cinnamate in $81 \%$ yield (entry 6 ). The catalytic activity of 10 was compared with those of $\mathrm{PdCl}_{2}$ (dithia[3.3](2,6)pyridinophane) $\mathbf{1 1}$ (entries 8 and 9, Table 1) and $\mathrm{PdCl}_{2}$ (2,2'-bipyridine) 12 (entries 10 and 11, Table 1). Complexes 11 and 12 showed good catalytic activities and afforded $t$-butyl cinnamate in $90 \%$ and $73 \%$ yields (entries 9 and 11, Table 1), respectively. However, longer reaction time was required to complete this reaction. It is considered that electron density of palladium in polymer complex $\mathbf{1 0}$ is higher than that in $\mathbf{1 1}$ and $\mathbf{1 2}$ due to the electron-donation from the electron rich alkoxyphenylene units to the pyridinophane units in $\mathbf{1 0}$. Thus, this conjugation effect in polymer complex $\mathbf{1 0}$ enhances the oxidative addition of aryl halide to palladium.

(Table 1)

(Structures of $\mathbf{1 1}$ and 12)

\subsection{Optical properties}

The UV-vis absorption spectra of polymer 13, which has dihexyloxyphenylene moieties $\left(M_{\mathrm{n}}=4200\right.$, PDI $\left.=2.3\right)$, and model compound 14 [18] are depicted in Figure 5. Polymer 13 exhibited a maximum absorption peak at $377 \mathrm{~nm}$ derived from the typical $\pi-\pi^{*}$ transition of PAE moieties, and the absorption edge was observed at around $500 \mathrm{~nm}$. Compound $\mathbf{1 4}$ had a spectrum similar to that of polymer 13 with the maximum absorption peak at $374 \mathrm{~nm}$ and the absorption edge at around $430 \mathrm{~nm}$, as shown in Figure 5. The through-space interaction of the dithia[3.3] $(2,6)$ pyridinophane unit appears to be less effective for the extension of $\pi$-conjugation due to conformational flexibility, which is similar to the case of the dithia[3.3]metacyclophane-containing polymer.

(Structure of polymer 13 and compound 14)

(Figure 5) 
The emission spectrum of polymer 13 at $464 \mathrm{~nm}$ (fluorescence quantum efficiency of $0.14)$ in the visible greenish-blue region in dilute $\mathrm{CHCl}_{3}$ solution $\left(1.0 \times 10^{-5} \mathrm{M}\right)$ is shown in Figure 6. The emission spectrum of $\mathbf{1 3}$ appeared to be featureless and did not have a vibrational structure. However, based on the emission spectrum of the dithia[3.3]metacyclophane-containing polymer 3, and the similar spectra of polymer $\mathbf{1 3}$ and compound 14 [18b], it is supposed that the emission spectrum of $\mathbf{1 3}$ is the same as that of the pyridine-containing arylene-ethynylene unit possessing an inconspicuous vibrational structure. Additionally, the emission spectrum of polymer 13 would be derived from the monomer state, which is the same as that of polymer 3. The maximum emission peak of polymer $\mathbf{1 3}$ appeared at $464 \mathrm{~nm}$, and it was red-shifted as compared to that of polymer $3\left(\lambda_{\max }=440 \mathrm{~nm}\right)$ because of an intramolecular donor-acceptor effect caused by the electron-accepting pyridine ring.

(Figure 6)

Figure 6 shows the photoluminescence spectra of polymer complexes with $80 \% \operatorname{Pd}(\mathrm{II})$ and $\mathrm{Pt}(\mathrm{II})$ obtained by the complexation between $\mathrm{PdCl}_{2}(\mathrm{PhCN})_{2}$ and $\mathrm{PtCl}_{2}(\mathrm{PhCN})_{2}$, respectively. The coordination of transition metals such as $\mathrm{Pd}(\mathrm{II})$ and $\mathrm{Pt}(\mathrm{II})$ affected the fluorescence emission property, and the emission spectra were significantly reduced. This result indicates the possible application of the dithia[3.3](2,6)pyridinophane-containing PAE in a transition metal sensor. 


\section{Conclusion}

In summary, we have synthesized conjugated polymers possessing the dithia[3.3]metacyclophane and dithia[3.3](2,6)pyridinophane units based on the PAE backbone. The polymers were readily synthesized by a palladium-catalyzed coupling reaction. The rapid syn-anti isomerization of dithia[3.3]metaphane in the PAE main chain was observed in solution. The through-space conjugation was ineffective in the ground state because of the flipping motion of the dithia[3.3]metaphane unit, and photoluminescence from the monomer state was observed in the excited state. Dithia[3.3](2,6)pyridinophane-containing PAE exhibited a coordination ability to transition metals such as palladium, and the conformation of the dithia[3.3](2,6)pyridinophane unit was folded in a syn form. This polymer complex acted as a recyclable catalyst for the conventional Heck coupling reaction. The photoluminescence of dithia[3.3](2,6)pyridinophane-containing PAE was considerably reduced by metal coordination, which suggests the possibility of applying this polymer in a heavy metal sensor. These findings will contribute to the design and synthesis of a novel PAE as well as through-space conjugated polymers utilizing their dynamic behavior and/or coordination ability. 


\section{Acknowledgments}

This work was supported by Grant-in-Aid for Creative Scientific Research of "Invention of Conjugated Electronic Structures and Novel Functions", No. 16GS0209, from the Ministry of Education, Culture, Sports, Science, and Technology, Japan. Financial support from the Mitsubishi Foundation is also acknowledged. T.I. appreciates Research Fellowships from the Japan Society for the Promotion of Science for Young Scientists. 


\section{References}

[1] (a) P.J. Stang, F. Diederich (Eds.), Modern Acetylene Chemistry, VCH, Weinheim, 1995; (b) F. Diederich, P.J. Stang, R.R. Tykwinski (Eds.), Acetylene Chemistry, Wiley-VCH, Weinheim, 2005.

[2] (a) U.H.F. Wunz, Chem. Rev. 100 (2000) 1605-1644; (b) C. Weder (Ed.), Adv. Polym. Sci., Poly(arylene ethynylene)s: From Synthesis to Application, Vol. 177, Springer, Berlin, 2005.

[3] (a) Y. Tohda, K. Sonogashira, N. Hagihara, Synthesis (1977) 777-8; (b) K. Sonogashira, in: E. Negishi (Ed.), Sonogashira Alkyne Synthesis, Handbook of Organopalladium Chemistry for Organic Synthesis, Wiley-VCH, New York, 2002, p. 493-529.

[4] (a) R.R. Schrock, D.N. Clark, J. Sancho, J.H. Wengrovius, S.F. Pederson, Organometallics 1 (1982) 1645-1651; (b) K. Weiss, A. Michel, E.M. Auth, U.H.F. Bunz, T. Mangel, K. Müllen, Angew. Chem. 36 (1997) 506-509.

[5] (a) Y. Morisaki, Y. Chujo, Macromolecules 35 (2002) 587-589; (b) Y. Morisaki, Y. Chujo, Chem. Lett (2002) 194-195; (c) Y. Morisaki, Y. Chujo, Macromolecules 36 (2003) 9319-9324; (d) Y. Morisaki, T. Ishida, H. Tanaka, Y. Chujo, J. Polym. Sci.: Part A: Polym. Chem. 42 (2004) 5891-5899; (e) Y. Morisaki, N. Wada, Y. Chujo, Polym. Bull. 53 (2005) 73-80; (f) Y. Morisaki, N. Wada, Y. Chujo, Polymer 46 (2005) 5884-5889; (g) Y. Morisaki, Y. Chujo, Angew. Chem. Int. Ed. 45 (2006) 6430-6437; (h) Y. Morisaki, Y. Chujo, Prog. Polym. Sci. 33 (2008) 346-364.

[6] (a) Y. Morisaki, Y. Chujo, Tetrahedron Lett. 46 (2005) 2533-2537; (b) Y. Morisaki, T. Murakami, Y. Chujo, Macromolecules 41 (2008) 5960-5963.

[7] F, Vögtle (Ed.), Cyclophane Chemistry, Wiley \& Sons, New York, 1993, p. 217-230.

[8] (a) M.F. Semmelhack, J.J. Harrison, D.C. Young, A. Gutiérrez, S. Rafii, J. Clardy, J. Am. Chem. Soc. 107 (1985) 7508-7514; (b) R.H. Mitchell, J. Am. Chem. Soc. 124 (2002), $2352-2357$.

[9] (a) Y. Morisaki, T. Ishida, Y. Chujo, Polym. J. 35 (2003) 501-506; (b) Y. Morisaki, T. Ishida, Y. Chujo, Polym. Bull. 57 (2006) 623-630.

[10] Y. Morisaki, T. Ishida, Y. Chujo, Org. Lett. 6 (2006) 1029-1032. 
[11] T. Kawashima, S. Kurioka, Y. Tohda, M. Ariga, Y. Mori, and S. Misumi, Chem. Lett. (1985) 1289.

[12] (a) F. Vögtle, P. Neumann, Tetrahedron 26 (1970) 5299-5318; (b) V. Boekelheide, C.H. Tsai, J. Org. Chem. 38 (1973) 3931-3934.

[13] R.S. Givens, R.J. Olsen, P.L. Wylie, J. Org. Chem. 44 (1979) 1608-1613.

[14] T. Otsubo, M. Kitasawa, S. Misumi, Bull. Chem. Soc. Jpn. 52 (1979) 1515-1520.

[15] P. Rademacher, in Modern Cyclophane Chemistry, R. Gleiter, H. Hopf (Eds.), Wiley-VCH, Weinheim, Germany, 2004, p. 275-310.

[16] (a) W.J. Oldham Jr, Y.J. Miao, R.J. Laghicotte, G.C. Bazan, J. Am. Chem. Soc. 120 (1998) 419-20; (b) G.C. Bazan, W.J. Oldham Jr, R.J. Lachicotte, S. Tretiak, V. Chernyak, S. Mukamel, J. Am. Chem. Soc. 120 (1998) 9188-9204; (c) S. Wang, G.C. Bazan, S. Tretiak, S. Mukamel, J. Am. Chem. Soc. 122 (2000) 1289-1297.

[17] T. Moriguchi, S. Kitamura, K. Sakata, A. Tsuge, Polyhedron 20 (2001) 2315-2320.

[18] (a) S.S. Sun, A.J. Lees, Inorg. Chem. 38 (1999) 4181-4182; (b) S.S. Sun, A.J. Lees, J. Photochem. Photobiol. A: Chem. 140 (2001) 157-161. 
Table 1. Catalytic activity on Heck reaction

\begin{tabular}{|c|c|c|c|c|}
\hline entry & cat. & $\mathrm{mol} \%^{\mathrm{a}}$ & time $/ \mathrm{h}$ & yield $^{\mathrm{b}} / \%$ \\
\hline 1 & 10 & 1.0 & 1 & 98 \\
\hline 2 & 10 & 0.05 & 1 & 90 \\
\hline 3 & 10 & 0.05 & 24 & 93 \\
\hline $4^{\mathrm{c}}$ & 10 & 0.05 & 1 & 91 \\
\hline $5^{\mathrm{d}}$ & 10 & 0.05 & 1 & 85 \\
\hline $6^{\mathrm{e}}$ & 10 & 0.05 & 1 & 81 \\
\hline 7 & 10 & 0.01 & 24 & 86 \\
\hline 8 & 11 & 0.05 & 1 & trace \\
\hline 9 & 11 & 0.05 & 24 & 90 \\
\hline 10 & 12 & 0.05 & 1 & 8 \\
\hline 11 & 12 & 0.05 & 24 & 73 \\
\hline
\end{tabular}

Determined by GLC based on the amount of phenyl iodide charged. ${ }^{\mathrm{c}}$ The reaction was performed in air. d 2 nd cycle. ${ }^{\mathrm{e}} 3$ rd cycle. 


\section{Captions}

Chart 1. [2.2]Paracyclophane-containing PAEs.

Fig. 1. Schematic representation of syn-[anti]-syn isomerization of the dithia[3.3]metacyclophane moiety, and ${ }^{1} \mathrm{H}$ NMR spectra in $\mathrm{CDCl}_{3}$ solution at room temperature; (A) monomer 1, (B) model compound 4, (C) polymer 3, and (D) polymer 5.

Fig. 2. UV-vis absorption spectra of polymer $\mathbf{3}$ and model compounds $\mathbf{4}$ and $\mathbf{6}$ in $\mathrm{CHCl}_{3}$ solution $\left(2.0 \times 10^{-5} \mathrm{M}\right)$ at room temperature.

Fig. 3. Fluorescence emission spectra of polymer 3 and compounds $\mathbf{6}$ in dilute $\mathrm{CHCl}_{3}$ solution $\left(1.0 \times 10^{-5} \mathrm{M}\right)$ at room temperature.

Fig. 4. ${ }^{1} \mathrm{H}$ NMR spectra at room temperature; (A) monomer 7 in $\mathrm{CDCl}_{3}$, (B) polymer 9 in $\mathrm{CDCl}_{3}$, and (C) polymer complex 10 in DMSO- $d_{6}$.

Fig. 5. UV-vis absorption spectra of polymer 13 and compound 14 in $\mathrm{CHCl}_{3}\left(2.0 \times 10^{-5} \mathrm{M}\right)$ at room temperature.

Fig. 6. Photoluminescence spectra of polymer 13 in $\mathrm{CHCl}_{3}\left(1.0 \times 10^{-5} \mathrm{M}\right)$ excited on 377 $\mathrm{nm}$ at room temperature, and polymer 13 with $80 \%$ of $\mathrm{Pd}(\mathrm{II})$ and $\mathrm{Pt}(\mathrm{II})$ in $\mathrm{CHCl}_{3}\left(1.0 \times 10^{-5}\right.$ M) excited on $400 \mathrm{~nm}$ at room temperature. 


\section{Scheme 1}

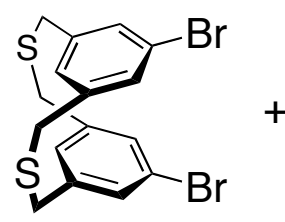

1

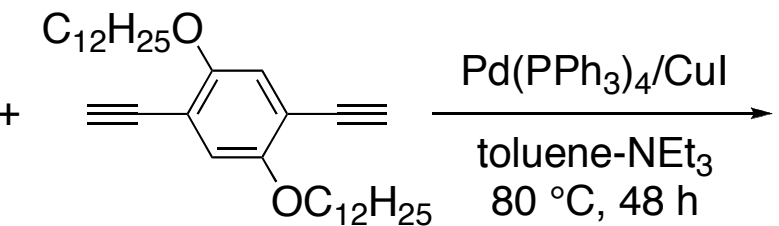

2

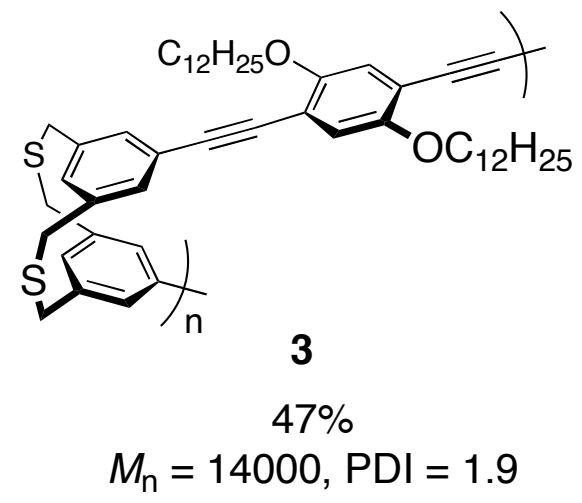


Scheme 2
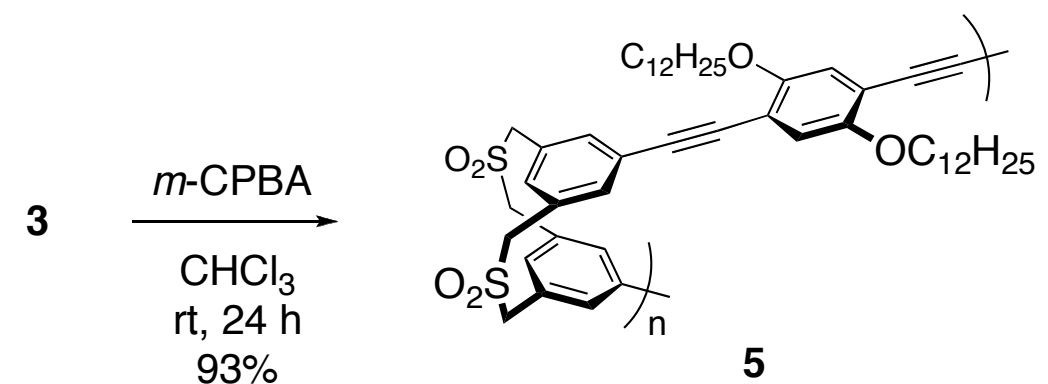


\section{Scheme 3}
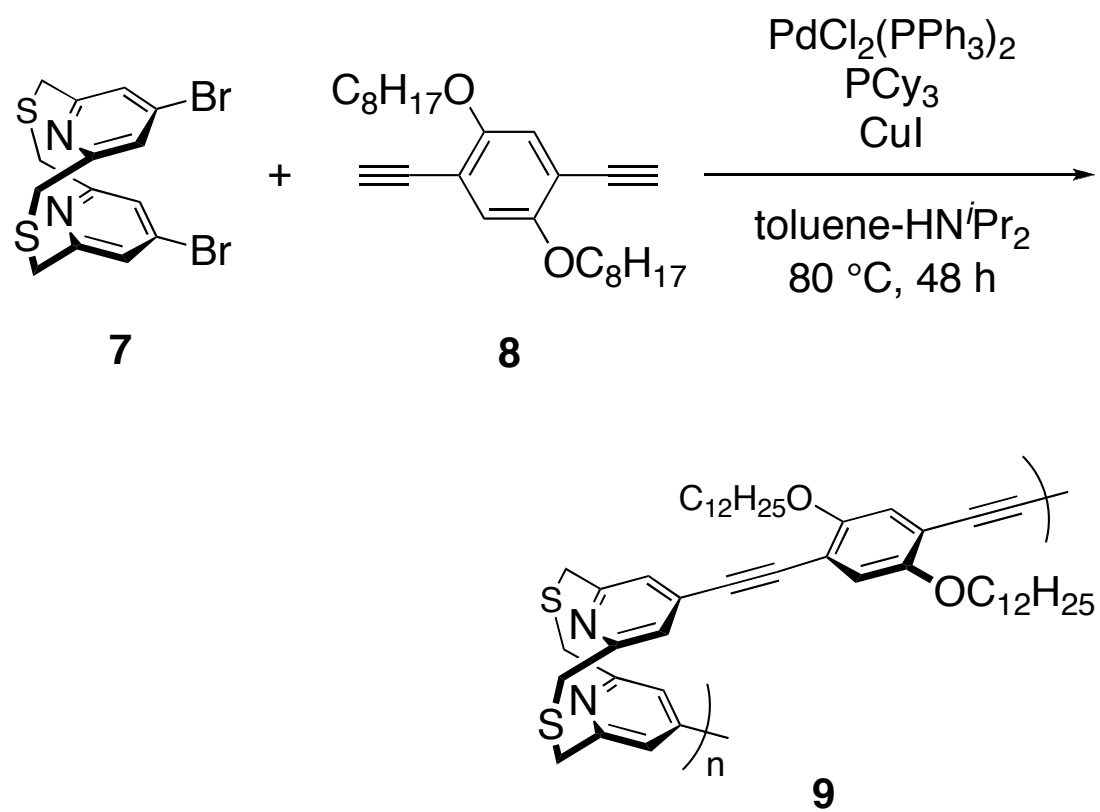

$$
\begin{gathered}
81 \% \\
M_{\mathrm{n}}=4200, \mathrm{PDI}=2.7
\end{gathered}
$$


Scheme 4

$$
9 \underset{\mathrm{PdCl}_{2}(\mathrm{PhCN})_{2}}{\stackrel{\mathrm{CH}_{2} \mathrm{Cl}_{2}}{\longrightarrow}}
$$

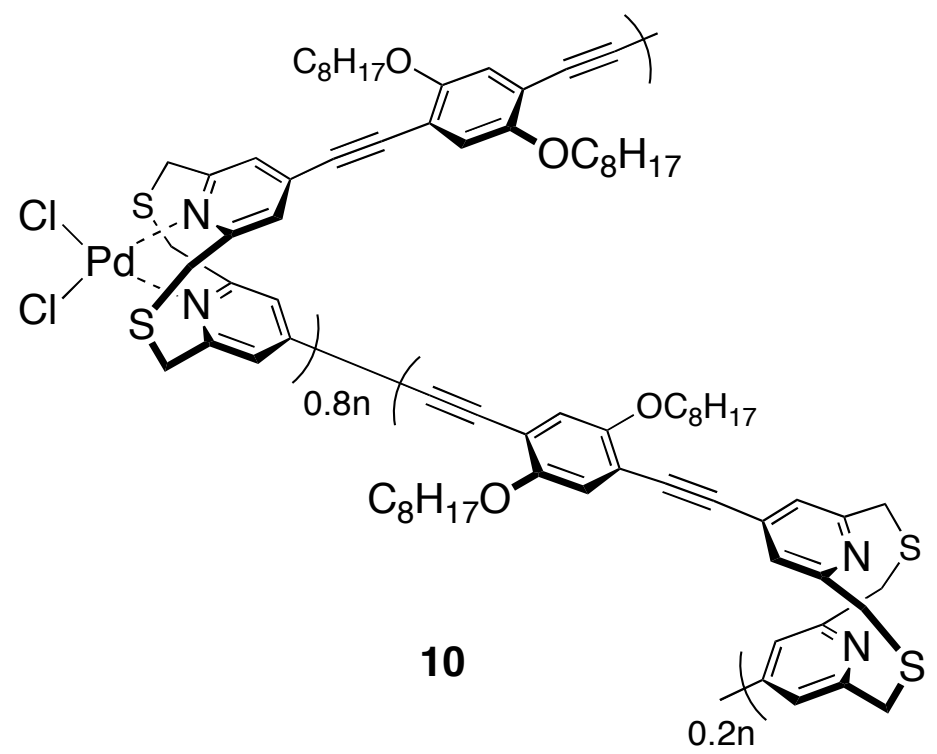




\section{Structure of 4}

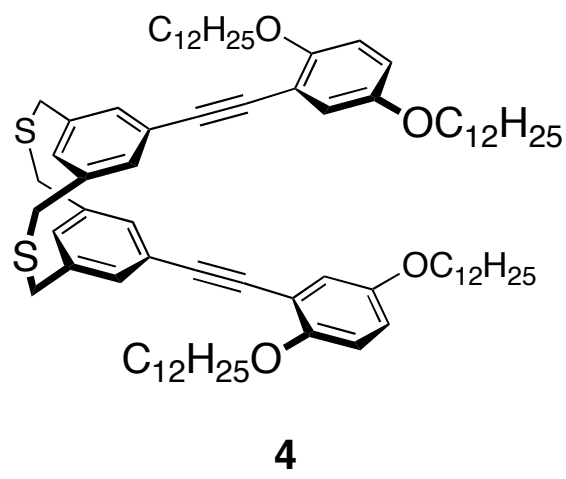

Structure of 6

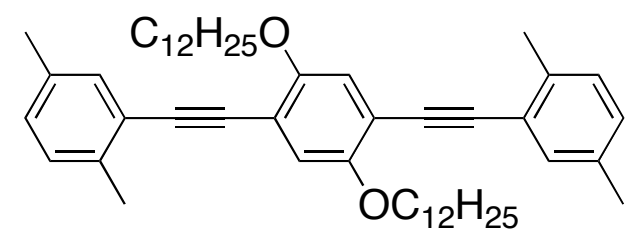

6

Structures of 11 and 12<smiles>Cl[Pb]1(Cl)SCc2cccc(n2)S1</smiles>

11<smiles></smiles>

12 
Structures of 13 and 14

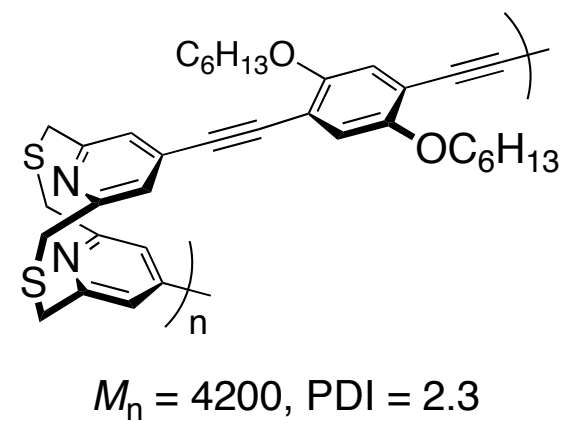

13

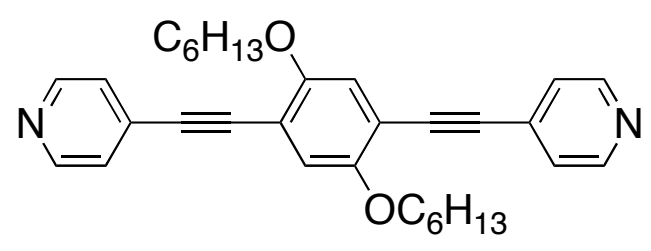

14 


\section{Chart 1}
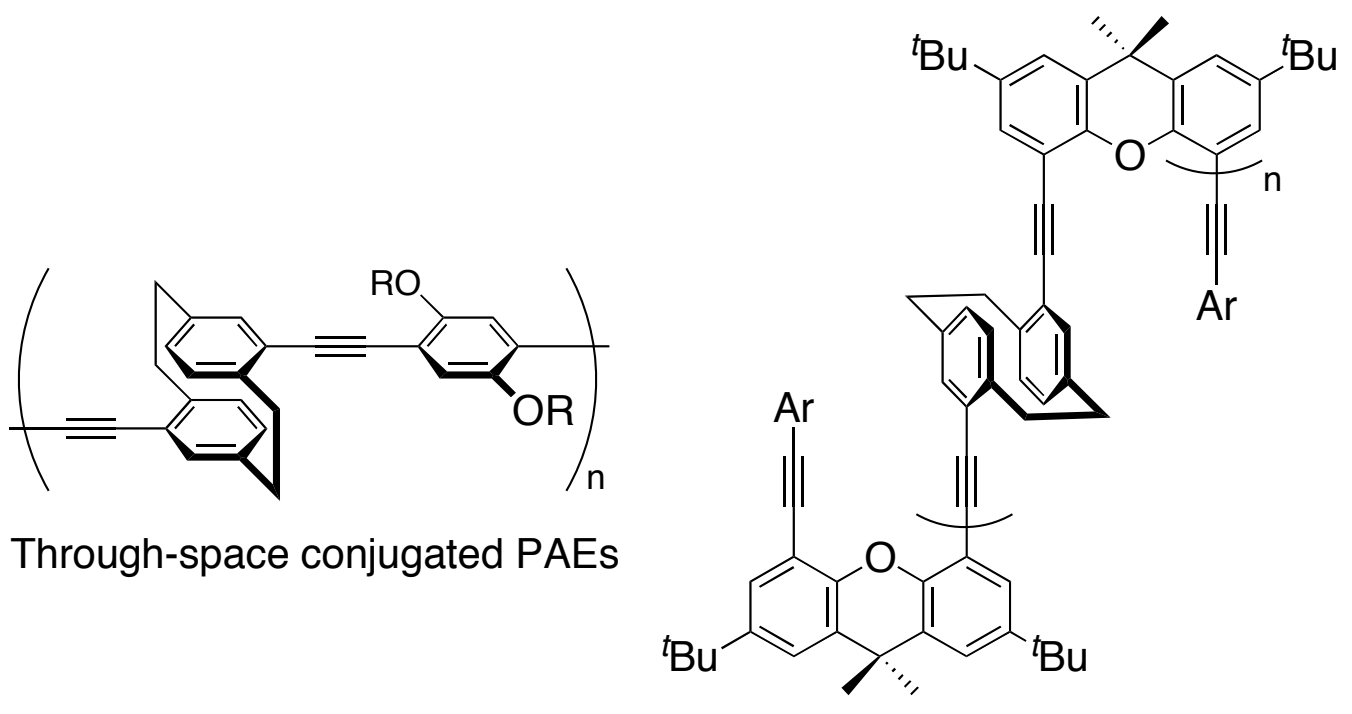

Aromatic ring-layered PAEs

Chart 1. [2.2]Paracyclophane-containing PAEs. 